\title{
Inovação na gestão da Estratégia de Saúde da Família: um relato de experiência
}

\author{
Giovane de Lelis Cupertino, Alessandra Montezano de Paula Carvalho, Franciane Silva Luís
}

\section{Resumo}

No âmbito do Sistema Único de Saúde, a Estratégia Saúde da Família (ESF) configura-se como o principal método de reorientação do modelo assistencial e de qualificação da atenção básica. Inserida em um contexto de decisão política e institucional, suas diretrizes apontam para uma nova dinâmica na estrutura organizacional dos serviços e ações de saúde. A Organização Mundial da Saúde reconhece que, para atender às expectativas das populações é essencial garantir a cobertura universal avançando na promoção, proteção e recuperação da saúde. Para isso, é fundamental que os gestores da saúde estejam aptos a trabalhar de forma inovadora na organização dos serviços de saúde. Relatar a experiência vivenciada na gestão em saúde do município de Ervália-MG. Trata-se de um relato de experiência realizado no município de Ervália-MG durante vinte dias de estágio extracurricular na ESF em 2015, nos quais foi possível acompanhar o desenvolvimento de estratégias e implementação de políticas inovadoras no âmbito da gestão da ESF. Como técnica de coleta de dados foram realizados métodos observacionais do campo de prática e consultas informais com os gestores e profissionais da saúde. Dentre as estratégias desenvolvidas pelo município destacam-se - a implantação da informatização da atenção básica utilizando a tecnologia e-SUSAB que, segundo os profissionais de saúde da cidade, vem proporcionando um ganho significativo no que se refere a otimização do tempo, organização dos dados e a facilidade em acessar os dados da ficha do paciente. Além disso, ocorreu a implantação dos Sistemas de Informação do Câncer (SISCAN) com o objetivo de reduzir o tempo de espera da mulher para receber os resultados dos exames preventivo e mamografia. De acordo com as enfermeiras de uma das unidades de saúde, este objetivo foi alcançado devido à melhoria do acesso ao resultado dos exames (em até 15 dias) pelo SISCAN. Os profissionais de saúde e o gestor local ressaltam que a redução desse tempo de espera contribui significativamente para o início do tratamento em alguma alteração patológica. Vale ressaltar também a eficácia no que se refere à articulação dos profissionais da ESF com o Núcleo de Apoio à Saúde da Família (NASF), o que proporcionou a diminuição da sobrecarga de trabalho da ESF e promoveu maior resolutividade dos casos, principalmente os que necessitam de intervenção da assistência social, terapia ocupacional e, ou psicologia. Observa-se que essas inovações na gestão proporcionou benefícios para a população. Contudo, tal êxito foi possível devido aos gestores e profissionais de saúde estarem sempre em consonância durante todo o processo de implantação, recebendo treinamentos adequados sobre as novas tecnologias, proporcionando assim uma melhor compreensão sobre a importância da implementação dessas novas estratégias e consequentemente a melhora da qualidade da atenção básica. Entretanto, os gestores reforçam que é necessário estar sempre atualizando os profissionais acerca do funcionamento dos sistemas de informação e conscientizando os que ainda apresentam resistência a essas estratégias.

Descritores: Gestão em saúde; Saúde da Família; Sistemas de Informação 